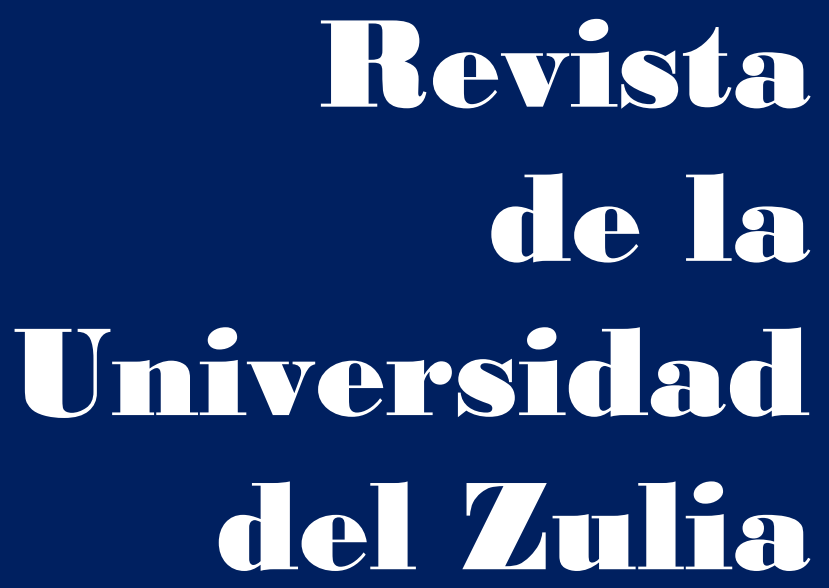

Fundada en 1947

por el Dr. Jesús Enrique Lossada

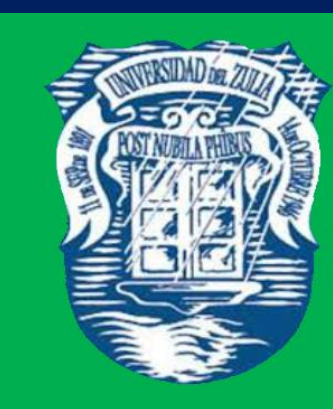

Ciencias del

Agrad,

Ingemiería

y Tecinología

\section{Aกัต 13 No $\mathbf{3 6}$} Enero - Abril 2022

Tercera Épaca

Maracailbo-Venezuela 
REVISTA DE LA UNIVERSIDAD DEL ZULIA. 3épeca. Año 13 Nº 36, 2022 Oshiel Martínez Chapa et al. /// Comercio y desarrollo México-Estados Unidos: una aproximación, 28-55

DOI: http://dx.doi.org/10.46925//rdluz.36.03

\title{
Comercio y desarrollo México-Estados Unidos: una aproximación
}

\author{
Oshiel Martínez Chapa * \\ Jorge Eduardo Salazar Castillo ** \\ Saul Roberto Quispe Aruquipa ***
}

RESUMEN

El propósito general de este trabajo es analizar la agenda de comercio y desarrollo binacional entre México y Estados Unidos (EU), en lo que concierne a los apartados comercio bilateral, remuneraciones y relaciones laborales, Derechos Humanos, seguridad fronteriza y cooperación contra el crimen, así como migración. Se justifica relevante dada la transición de gobierno en EU y sus implicaciones para México. Considerando las estadísticas y documentos de las variables seleccionadas se plantea la necesidad de ir a mayor profundidad en estos asuntos de la agenda bilateral en el marco del Derecho Internacional y la Diplomacia y su ánimo conciliador para beneficio común.

PALABRAS CLAVE: Comercio internacional; remuneración; Derechos Humanos; seguridad internacional; migración.

*Docente. Tecnológico Nacional de México y Universidad Autónoma de Tamaulipas, México. ORCID: https://orcid.org/0000-0001-9675-5472.E-mail: omartinez@docentes.uat.edu.mx

**Docente. Universidad Autónoma de Tamaulipas, México. ORCID: https://orcid.org/0000-0002-11382353. E-mail: jorge@uat.edu.mx

*** Docente. Universidad Autónoma Metropolitana, México. ORCID: https://orcid.org/0000-00023018-2832.E-mail: saul_rqa@yahoo.es

Recibido: 04/10/2021

Aceptado: 01/12/2021 
REVISTA DE LA UNIVERSIDAD DEL ZULIA. 3épeca. Año 13 N $^{\circ}$ 36, 2022 Oshiel Martínez Chapa et al. /// Comercio y desarrollo México-Estados Unidos: una aproximación, 28-55 DOI: http://dx.doi.org/10.46925//rdluz.36.03

\section{Mexico-United States Trade and Development: An Approach}

ABSTRACT

The general purpose of this work is to analyze the binational trade and development agenda between Mexico and the United States (US), regarding the sections of bilateral trade, wages and labor relations, Human Rights, border security and cooperation against crime. as well as migration. Relevance is justified given the transition of government in the US and its implications for Mexico. Considering the statistics and documents of the selected variables, the need is raised to go deeper into these matters on the bilateral agenda within the framework of International Law and Diplomacy and its conciliatory spirit for common benefit.

KEY WORDS: International trade; remuneration; Human Rights; International security; migration.

\section{Introducción}

El tema del comercio internacional (CI) y de aquellos que están implícitos en las relaciones de los países siempre se halla vigente. De hecho, lo está más ahora, dadas las intenciones de algunos países respecto de revisar las relaciones comerciales que se advierten recientemente como EU y el Reino Unido. El propósito de este trabajo es analizar la agenda de comercio y desarrollo binacional entre México y Estados Unidos (EU), relativos a los aspectos del comercio bilateral, remuneraciones y relaciones laborales, Derechos Humanos, seguridad fronteriza y cooperación contra el crimen, así como migración. La relación histórica entre estos países ha manifestado altibajos, inclusive de grado bélico. Existe un esfuerzo de ambos gobiernos para mejorar el bienestar ciudadano, además de implementar acciones para favorecer el comercio más libre.

La relación entre México y EU nunca ha sido un asunto sencillo, ya que a lo largo de su historia se han experimentado encuentros y desencuentros. En algunos periodos las relaciones comerciales y diplomáticas han sido estables en lo general. Sin embargo, en forma particular la administración del presidente Trump (2016-2020) se caracterizó por una política exterior hacia México de exigencias de cooperación en los temas de seguridad fronteriza y la revisión del Tratado de Libre Comercio de América del Norte (TLCAN), fundamentalmente. El asunto 
REVISTA DE LA UNIVERSIDAD DEL ZULIA. 3é época. Año 13 N $^{\circ}$ 36, 2022 Oshiel Martínez Chapa et al. /// Comercio y desarrollo México-Estados Unidos: una aproximación, 28-55 DOI: http://dx.doi.org/10.46925//rdluz.36.03

migratorio y los demás constituyeron una prioridad para su gobierno. Ahora con el presidente Biden, la situación requiere un abordaje de estas temáticas dado que siguen siendo relevantes.

Sería muy deseable que se privilegiaran la cooperación y desarrollo entre las naciones; más aún si son vecinas. Sin embargo, no siempre ello se privilegia. Las partes involucradas debieran reconocen la necesidad de construir acuerdos políticos, de comercio y cooperación de cara a reducir a las desigualdades entre ellos. En el siglo XX las relaciones comerciales de México y EU se caracterizaron por una gradual reducción de los derechos de importación y de los gravámenes aplicados a las importaciones. Las exportaciones de México hacia EU se limitaron a materias primas y metales preciosos.

Con el transcurso del tiempo, ya en el marco de la liberalización comercial de los ochenta, participaron en mayor medida las manufacturas de mayor valor agregado. Las de EU hacia México fueron, en su mayoría, alimentos procesados, bienes agrícolas, tecnología, equipo y gas, gasolina y demás energéticos. En buena medida el gobierno mexicano fue abandonando su política industrial proteccionista, lo cual le permitió adecuarse a las exigencias norteamericanas. Los altos aranceles decretados por México tuvieron el propósito de obtener ingresos aduaneros extraordinarios, pero fueron reduciéndose con la liberalización de la economía nacional (Martínez et al., 2021).

De acuerdo con la oficina representativa de comercio de los EU, en 2019 el volumen de comercio entre este país y México fue de 6,673 billones USD, de las cuales fueron de 289.5 billones en exportaciones y de 387.8 billones por concepto de importaciones. De ese modo, México se constituye en el principal socio comercial de los EU.

Las exportaciones de EU a México han crecido a aproximadamente un 517 \% de 1993 al 2021. Las principales compras realizadas por México son: maquinaria (45 billones de USD); maquinaria eléctrica (42); combustibles minerales (34); vehículos (21); plásticos (16) y productos agrícolas (20). Las exportaciones de servicios se estimaron en 32.9 billones USD desde en el mismo periodo por concepto de viajes, transporte y propiedad intelectual fundamentalmente.

Por su parte, México se ha convertido en el segundo proveedor de los EU, después de China, y los bienes que exporta son: vehículos (101 billones de USD); maquinaria (66); 
REVISTA DE LA UNIVERSIDAD DEL ZULIA. 3é época. Año 13 N $^{\circ}$ 36, 2022 Oshiel Martínez Chapa et al. /// Comercio y desarrollo México-Estados Unidos: una aproximación, 28-55 DOI: http://dx.doi.org/10.46925//rdluz.36.03

maquinaria eléctrica (64); instrumentos ópticos y médicos (16); combustibles minerales (13); productos agrícolas (28). Las exportaciones de México a EU han crecido alrededor del 30 por ciento en el periodo referido. La inversión extranjera directa en México fue de 100.9 billones de USD en 2019, y se ha realizado en sectores como la manufactura, finanzas, seguros, hotelería y demás servicios.

Los dos países comparten una frontera de 2,000 millas con 55 puertos de entrada terrestres activos, y las relaciones bilaterales entre ambos tienen un impacto directo en la vida y los medios de subsistencia de millones de estadounidenses, ya sea que se trate de reformas comerciales y económicas, intercambio educativo, seguridad ciudadana, control de drogas, migración, trata de personas, emprendimiento, innovación, cooperación energética o salud pública. El alcance de las relaciones entre EU y México es amplio y va más allá de las relaciones diplomáticas y oficiales. Abarca amplios lazos comerciales, culturales y educativos, con \$ 1.7 billones USD de comercio de ida y vuelta y durante tiempos económicos y de salud normales; hay cientos de miles de personas que cruzan la frontera legalmente cada día (US Departament of State, 2021).

El Tratado México, Estados Unidos y Canadá (T-MEC) o USMCA por sus siglas en inglés, entró en vigor el 1 de julio de 2020. El T-MEC apoyará el comercio de beneficio mutuo que conducirá a mercados más libres, un comercio más justo y un crecimiento económico sólido en América del Norte. Se espera que el citado Acuerdo genere oportunidades laborales; mejore la protección de los trabajadores; prevenga el trabajo forzoso; incremente el comercio agrícola; aliente nuevas inversiones en industrias manufactureras vitales; proteja los derechos de propiedad intelectual; propicie un conjunto similar de estándares ambientales en los tres países; y trasladar las protecciones comerciales digitales al siglo XXI (US Departament of State, 2021).

De acuerdo con el Departamento de Agricultura de EU (US Department of Agriculture, 2020) el comercio agrícola entre EU y México es fundamentalmente complementario, lo que significa que dicho país tiende a exportar diferentes productos básicos a México. Aproximadamente tres cuartas partes de las exportaciones agrícolas de EU a México son cereales, semillas oleaginosas, carne o productos relacionados. México no produce suficientes granos y oleaginosas para satisfacer la demanda interna, por lo que los productores de alimentos 
REVISTA DE LA UNIVERSIDAD DEL ZULIA. 3é época. Año 13 N $^{\circ}$ 36, 2022 Oshiel Martínez Chapa et al. /// Comercio y desarrollo México-Estados Unidos: una aproximación, 28-55 DOI: http://dx.doi.org/10.46925//rdluz.36.03

y ganado importan volúmenes considerables de estos productos básicos para fabricar productos de valor agregado como carne, aceite vegetal y productos de trigo.

El desarrollo económico de los países requiere de los factores productivos indispensables, además de una serie de arreglos institucionales. A lo largo de la historia las naciones imperialistas han echado mano de dichos arreglos políticos. En el caso de México, a finales del siglo XIX y comienzos del XX — en la época del porfiriato- las inversiones de nacionales y extranjeros crecieron de manera significativa. Bajo el lema de orden y progreso se realizaron inversiones en infraestructura como la construcción de vías férreas, presas, comunicaciones y demás. La frontera norte, como también el sur y amplias regiones del país sufrieron de desatención. Era de esperar con ello que los asuntos fundamentales como la justicia social, la falta de libertades y de desarrollo se dejaron de lado; razones que alentaron la Revolución mexicana. En términos reales esta situación pone de manifiesto que el modelo de economía que privilegió a los ricos entró en grave crisis.

El presente trabajo se estructura de la siguiente manera: En la primera parte se revisa la literatura y destaca la importancia del comercio binacional México-EU y cómo este se ha trasformado en un contexto de liberación y expansión global de los mercados. La segunda parte se refiere a los métodos y resultados se analizan datos que tienen que ver con la dinámica comercial y no comercial, señalándose los aspectos fundamentales característicos de dicha agenda binacional. La última parte destaca las conclusiones.

\section{Revisión de la literatura}

El comercio internacional (CI) constituye uno de los fundamentos del desarrollo, pues en él ocurren intercambios de bienes y servicios entre dos o más países o regiones económicas. Las economías que participan de él se denominan economías abiertas (Samuelson y Nordahus, 2010). Como antecedentes del CI en el siglo XX deben señalarse a las reuniones de Bretton Woods en 1944 y la materialización del Acuerdo General sobre Aranceles Aduaneros y Comercio (GATT) en 1948. La Organización Mundial de Comercio (OMC) se creó en 1995 como institución de fomento, regulación y arbitraje entre los países. Durante ese periodo el intercambio de 
REVISTA DE LA UNIVERSIDAD DEL ZULIA. 3é época. Año 13 N $^{\circ}$ 36, 2022 Oshiel Martínez Chapa et al. /// Comercio y desarrollo México-Estados Unidos: una aproximación, 28-55 DOI: http://dx.doi.org/10.46925//rdluz.36.03

mercancías estuvo regido por un conjunto de normas diseñadas para reducir las barreras arancelarias y no arancelarias a partir de la implementación de varias rondas de negociaciones. Este proceso de liberalización global cobró dinamismo en la década de los noventa, al incorporarse a las economías de Latino América, de Europa del Este y del sur de Asia. El resultado ha sido una mayor interrelación comercial y no comercial en los mercados internacionales.

En estos procesos de liberalización de la economía mundial las corporaciones pretenden alcanzar los más altos niveles de competitividad en base a elevados estándares de desempeño y rentabilidad, considerando reducir los costos de producción y demás condiciones favorables para la expansión de sus operaciones. Por su parte, Mendoza Cota (2021) destaca que la inversión extranjera directa en México ha sido positiva en el contexto de la liberalización comercial. Además de ello, las relaciones con EU han experimentado un crecimiento en las cadenas de valor entre ambos países. Así, las políticas de ambos países requieren del desarrollo de infraestructura y demás arreglos para la potenciación de dichas relaciones económicas.

Sobre las relaciones de comercio bilateral deben destacarse diversos trabajos, entre los cuales se encuentra el de Ortiz Valenzuela (2020), en el cual se plantea la necesidad de profundizar los acuerdos de vinculación en la industria automotriz entre Colombia y Venezuela. Así, en este tipo de acuerdos las empresas toman ventajas al acceder al financiamiento en las mejores condiciones, a las tecnologías de vanguardia, así como a mercados con mayor poder de compra. En la medida en que se hacen más globales, su identidad nacional se va perdiendo. En ese propósito, ha sido indispensable contar con la infraestructura de comunicaciones y transportes, acceso a tecnología, trabajo y demás arreglos institucionales.

Respecto a las relaciones comerciales en el contexto de bloques de países, la experiencia de América Latina no es la excepción. En estos países también se advierten los beneficios de la integración y de las economías de escala derivados de los arreglos institucionales que se han desarrollado a través del tiempo, especialmente en el largo plazo. Aunque no están exentos de dificultades y desacuerdos, existen patrones de estabilidad que dan cuenta de que la cooperación económica y la voluntad política son elementos que favorecen el desarrollo económico a partir de sus vínculos con el comercio internacional (Bejarano Copo et al, 2020). 
REVISTA DE LA UNIVERSIDAD DEL ZULIA. 3ª época. Año $13 \mathrm{~N}^{\circ}$ 36, 2022 Oshiel Martínez Chapa et al. /// Comercio y desarrollo México-Estados Unidos: una aproximación, 28-55 DOI: http://dx.doi.org/10.46925//rdluz.36.03

Según Daniels (2009) el CI está basado en una serie de condiciones que lo favorecen, entre las cuales se hallan las siguientes:

-La prevalencia del comercio como factor natural, a pesar de las restricciones de idioma, geografía, leyes y demás. La geografía está asociada al CI y ocurre de manera intencionada o no.

-La consideración de la existencia de mercados en el exterior ante las crisis nacionales.

La investigación de mercados como punta de lanza para colocar bienes y servicios, considerando los flujos de personas y de recursos en las diversas fronteras nacionales.

-La exportación de tecnologías y bienes innovadores, especialmente hacia países en vías de desarrollo.

-La formación de economías de escala debido a potenciación de los recursos físicos, materiales y humanos de dentro y de fuera del país.

-La extensión del ciclo de la vida de las empresas y sus bienes a otros países.

Por otro lado, el enfoque básico de la economía internacional para la inmigración es el teorema de Rybczynski (1955). Esta teoría, desde luego sujeta a un conjunto de suposiciones, se describe de la siguiente manera: un aumento en la dotación de trabajo del país a través de la inmigración aumentará más que proporcionalmente la producción de esos productos, cuya tecnología de producción requiere mucha mano de obra. Así, la producción de bienes intensivos en otros factores, por ejemplo, capital, tendrá que disminuir (Benacek, 2010: 70).

De acuerdo con Terrazas y Basante y Garza (2012) el CI presenta asimetrías, las cuales en el caso de México-EU significan un mayor control de los recursos y del comercio por parte de los EU. Esta situación ha significado mayor vulnerabilidad para la economía mexicana, especialmente en lo que concierne a la pérdida de un mayor mercado destino de sus exportaciones. Desde entonces, se evidencia una tendencia a concentrar el mercado y la producción en México. Se observa, adicionalmente, una seria dificultad para diversificar exitosamente las exportaciones mexicanas a otros mercados del exterior.

Por otro lado, según Reyes (2021: 1), la relación de México y EU en el actual contexto de cambio de gobierno en EU, ya como presidente Biden, puede ser agridulce y lo plantea de la siguiente forma: 
REVISTA DE LA UNIVERSIDAD DEL ZULIA. 3a época. Año $13 \mathrm{~N}^{\circ}$ 36, 2022 Oshiel Martínez Chapa et al. /// Comercio y desarrollo México-Estados Unidos: una aproximación, 28-55 DOI: http://dx.doi.org/10.46925//rdluz.36.03

"Además del comercio, hay una serie de temas que tradicionalmente han marcado la agenda bilateral: seguridad, migración, control del narcotráfico, cambio climático, política energética, respeto a los derechos humanos y condiciones laborales. La administración Biden basará su relación con México en el marco de un estricto cumplimiento de los compromisos establecidos bajo el T-MEC. Ello en principio debería ser benéfico para nuestro país, ya que el T-MEC ha sido reconocido por nuestro gobierno como un instrumento para promover el desarrollo. Sin embargo, hay algunos temas que Biden remarcará y en los que el gobierno mexicano tiene visiones diferentes como en los temas de energía y la promoción de energías limpias, la supervisión de la ley laboral y el control de la pandemia".

2. Métodos y resultados

El trabajo en cuestión es de tipo cualitativo fundamentalmente, pues partiendo del propósito general, así como revisión de la literatura, se procedió a recopilar los datos e información referentes a las variables de interés: el comercio entre México y EU, las remuneraciones (manufactureras) y relaciones laborales; Derechos Humanos; la seguridad fronteriza y cooperación contra el crimen, además de migración.

\subsection{Comercio binacional}

El primer aspecto que se revisa es el del comercio binacional México-EU. Para los propósitos perseguidos en la presente investigación es conveniente destacar el significado que tiene el comercio entre estos países. En 1988 EU y Canadá iniciaron su tratado bilateral. México se incorporó en 1994, creándose así el denominado TLCAN. En la conformación del citado bloque se establecieron reglas tendientes a incrementar los flujos comerciales y de inversión, así como a mejorar el empleo y el nivel de bienestar. Como oportunidades para el crecimiento de la economía mexicana el país tiene firmados diez acuerdos comerciales con 45 países, lo cual equivale al 60 por ciento del PIB mundial. Los principales acuerdos son el TLCAN y el firmado con la Unión europea (TLCUEM). También existen acuerdos con otros bloques y naciones por separados: Mercosur, Alianza del Pacífico, Israel, Japón, Centroamérica, entre otros.

En el contexto de la liberalización de la economía, la relación bilateral México-EU presenta la caracterización que muestra la tabla 1: 
REVISTA DE LA UNIVERSIDAD DEL ZULIA. 3épeca. Año 13 Nº 36, 2022 Oshiel Martínez Chapa et al. /// Comercio y desarrollo México-Estados Unidos: una aproximación, 28-55 DOI: http://dx.doi.org/10.46925//rdluz.36.03

Tabla 1 La relación bilateral México-EU en el contexto del TLCAN-TMEC

\begin{tabular}{|c|c|c|}
\hline & Para México & Para Estados Unidos \\
\hline 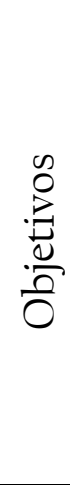 & $\begin{array}{l}\text { - Asegurar el acceso de la } \\
\text { tecnología, materias primas, } \\
\text { equipo y bienes finales de EU. } \\
\text { - Acceder a un mercado diverso y } \\
\text { con poder de compra. } \\
\text { - Atraer la inversión directa e } \\
\text { indirecta para generar empleos. }\end{array}$ & $\begin{array}{l}\text { - Integrar sus cadenas productivas y } \\
\text { complementar su producción de } \\
\text { recursos minerales. } \\
\text { - Detener la inmigración mexicana } \\
\text { - Aprovechar el capital humano } \\
\text { competitivo y con costos salariales } \\
\text { menores. } \\
\text { - Mejorar la competitividad respecto a } \\
\text { Europa, Japón y el sur de Asia. }\end{array}$ \\
\hline 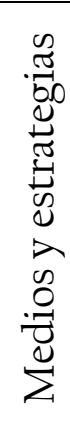 & $\begin{array}{l}\text { - Liberalizar el comercio } \\
\text { - Privatizar empresas estatales } \\
\text { - Atraer la inversión por la vía de } \\
\text { las reformas estructurales } \\
\text { (laboral y energética). } \\
\text { - Ajustar las políticas económicas a } \\
\text { nuevas condiciones } \\
\text { internacionales. }\end{array}$ & $\begin{array}{l}\text { - Especializar industria de alta } \\
\text { tecnología. } \\
\text { - Diversificar la economía: énfasis en } \\
\text { el comercio, el turismo y la } \\
\text { profundización financiera. } \\
\text { - Realizar inversiones, adquisiciones } \\
\text { y fusiones con empresas de México. }\end{array}$ \\
\hline
\end{tabular}

Fuente: Elaborado por los autores

Idealmente las relaciones entre los países debieran ser fructíferas y basadas en las reglas acordadas y la cooperación. No obstante, en la historia universal no son pocos los episodios de saqueo y explotación de recursos y personas en las naciones colonizadas. Los contrastes en el CI en lo concerniente a intercambios y valor agregado entre los países son descritos en los siguientes términos:

Las diferencias entre los países en vías de desarrollo y los desarrollados son mayores cuando se examina la composición del comercio. Los países en vías de desarrollo suelen ser exportadores de bienes básicos. Las materias primas, los cultivos destinados a los grandes mercados y a veces los productos alimenticios constituyen importantes artículos de exportación. Los textiles y los artículos de la industria ligera también figuran en la lista. En cambio, la mayor parte de las exportaciones de los países desarrollados pertenecen a la categoría de bienes manufacturados y van desde bienes de capital hasta bienes de consumo duradero (Ray, 2002: 37).

En este mismo orden de ideas, el crecimiento del PIB mundial ha mostrado un descenso en el ámbito internacional desde 2010 hasta el presente, explicado por la adopción de prácticas proteccionistas entre no pocos países; alentadas estas por el bajo crecimiento y la prevaleciente 
REVISTA DE LA UNIVERSIDAD DEL ZULIA. 3ª época. Año $13 \mathrm{~N}^{\circ}$ 36, 2022 Oshiel Martínez Chapa et al. /// Comercio y desarrollo México-Estados Unidos: una aproximación, 28-55 DOI: http://dx.doi.org/10.46925//rdluz.36.03

incertidumbre económica. Persisten aun prácticas de barreras arancelarias y no arancelarias, retrasos en las aduanas, nuevos impuestos y nuevas regulaciones que suelen afectar más a las naciones en vías de desarrollo.

De acuerdo con Burfisher et al (2001), dado el contexto del TLCAN, el mismo ha implicado diversidad de aspectos para los EU, entre los cuales deben destacarse los costos del ajuste derivados de la liberalización comercial, las políticas comerciales y los vínculos entre los acuerdos regionales y el comercio mundial.

La dinámica comercial de EU con otros países seleccionados se observa en la gráfica l. En la misma se muestra un patrón general de crecimiento de las exportaciones de EU con respecto a México, considerado un socio estratégico de larga data. Después del 2009 se observa un crecimiento importante en el comercio bilateral entre los países. Aunque la gráfica 1 no muestra datos del 2020, es un hecho que la dinámica referida ha sido menor, pues el Covid 19 ha afectado las inversiones y el comercio entre los países.

Las exportaciones de México han crecido significativamente a lo largo del periodo. De hecho, el balance comercial es desfavorable para EU. Sin embargo, el crecimiento de los cruces de personas y los flujos de transporte y comunicaciones confirman la importancia de la integración económica. Es muy significativo que los ciudadanos de ambas fronteras tengan más alternativas de consumo e inversión.

Pese a lo anterior, en su retórica, el gobierno mexicano ha expresado la confianza en que el libre comercio coadyuve al desarrollo nacional. Como otras naciones del Continente, el país está experimentado un cambio significativo en su orientación de política comercial, aunque esto último aún no se ha traducido en un mayor nivel de bienestar para el grueso de la población. Las políticas de liberación comercial desventajosas, aunadas a la carga fiscal creciente han contribuido al "malestar en la globalización", término descrito por Stiglitz (2011). Los efectos de estas políticas han sido contrarios a los objetivos prometidos por la clase gobernante, pues lejos de formalizar las actividades empresariales, se ha dado un crecimiento desmedido de mercados negros, empleo atípico y desempleo con graves consecuencias. 
REVISTA DE LA UNIVERSIDAD DEL ZULIA. 3é época. Año $13 \mathrm{~N}^{\circ}$ 36, 2022 Oshiel Martínez Chapa et al. /// Comercio y desarrollo México-Estados Unidos: una aproximación, 28-55 DOI: http://dx.doi.org/10.46925//rdluz.36.03

Gráfica 1. Comercio bilateral México-EU en millones de USD (2000-2019)

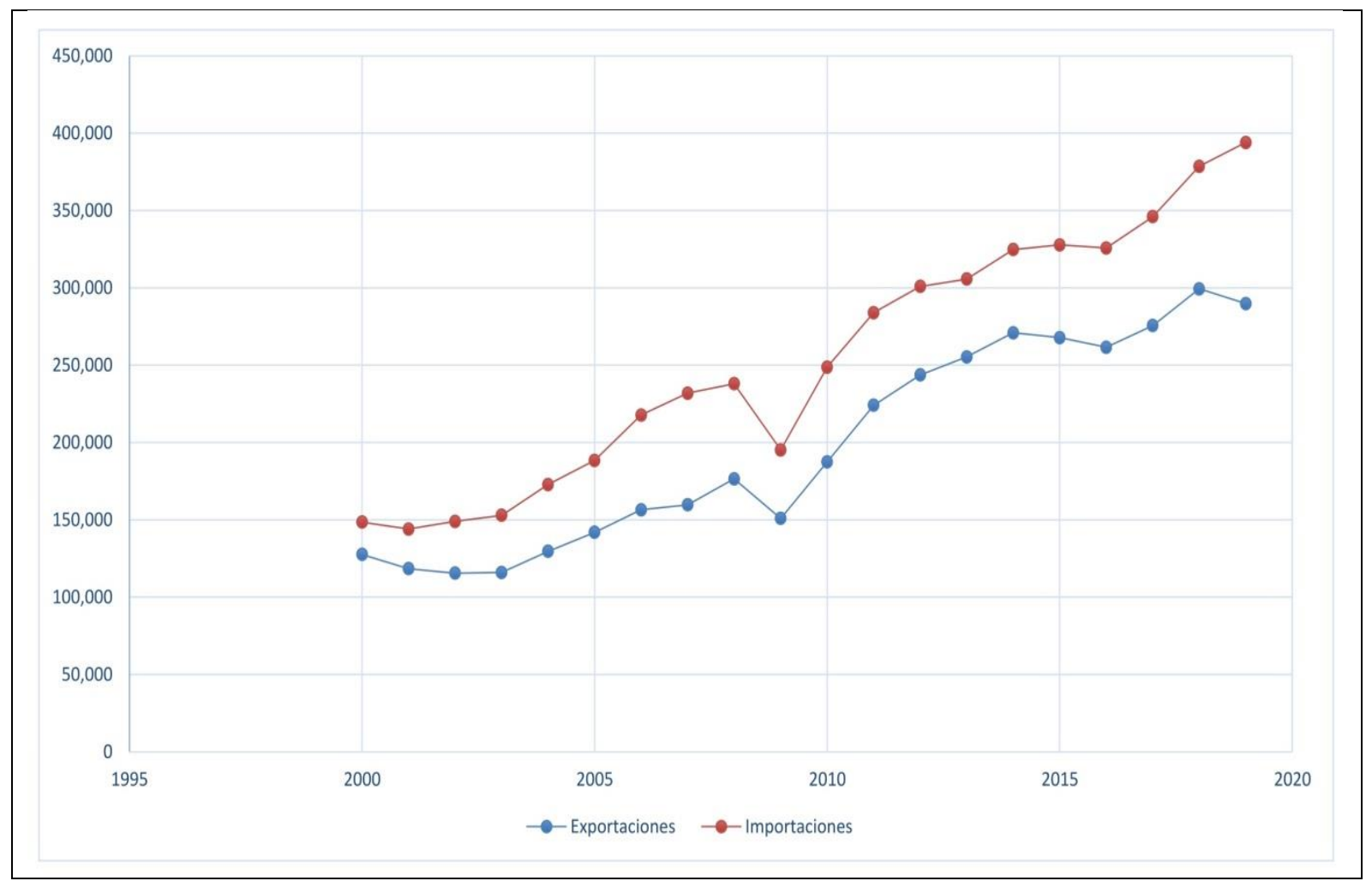

Fuente: Elaborado por los autores en base al Bureau of Economic Analysis, USA (2020).

La relación comercial de EU con otros países se caracteriza por las siguientes singularidades, las cuales se desprenden de la tabla 2. Con Canadá se han intensificado las transacciones comerciales las cuales tienden a equilibrarse. De hecho, por su vecindad y su acuerdo bilateral es de esperar un crecimiento mayor. Con China las relaciones comerciales han crecido exponencialmente, aunque el déficit se ha elevado con mayor rapidez; de ahí los motivos del expresidente Trump de limitar las relaciones con dicho país y buscar negociaciones donde EU pudiese obtener mayores beneficios. Con la Unión Europea han crecido las transacciones, pero el déficit tiende a persistir. Con respecto a los países de la Organización de Países Exportadores de Petróleo (OPEP), debe señalarse su crecimiento del volumen de exportaciones. Sin embargo, debido a la independencia energética que va adquiriendo, las importaciones de crudo han venido reduciéndose considerablemente. Con América Central y Sud América el comercio ha crecido, aunque aquí EU va logrando un superávit comercial. 
REVISTA DE LA UNIVERSIDAD DEL ZULIA. 3é época. Año $13 \mathrm{~N}^{\circ}$ 36, 2022 Oshiel Martínez Chapa et al. /// Comercio y desarrollo México-Estados Unidos: una aproximación, 28-55 DOI: http://dx.doi.org/10.46925//rdluz.36.03

Tabla 2: Comercio de EU con países seleccionados (en millones de USD)

\begin{tabular}{|c|c|c|c|c|}
\hline & Periodo & $\begin{array}{c}\text { Exportacione } \\
\text { s }\end{array}$ & $\begin{array}{c}\text { Importacione } \\
\text { s }\end{array}$ & Balance \\
\hline \multirow{4}{*}{ Canadá } & 2000 & 204,334 & 253,312 & $-48,978$ \\
\cline { 2 - 5 } & 2005 & 246,291 & 319,543 & $-73,252$ \\
\cline { 2 - 5 } & 2010 & 307,571 & 310,341 & $-2,770$ \\
\cline { 2 - 5 } & 2015 & 341,326 & 334,254 & 7,072 \\
\cline { 2 - 5 } China & 2019 & 361,226 & 363,893 & $-2,667$ \\
\hline & 2000 & 21,862 & 103,340 & $-81,478$ \\
\cline { 2 - 5 } & 2005 & 50,685 & 251,791 & $-201,106$ \\
\cline { 2 - 5 } & 2010 & 113,576 & 377,619 & $-264,043$ \\
\cline { 2 - 5 } & 2015 & 163,323 & 499,676 & $-336,353$ \\
\cline { 2 - 5 } & 2019 & 164,480 & 472,321 & $-307,841$ \\
\hline \multirow{5}{*}{ Unión Europea } & 2000 & 260,504 & 306,423 & $-45,919$ \\
\cline { 2 - 5 } & 2005 & 318,913 & 426,347 & $-107,434$ \\
\cline { 2 - 5 } & 2010 & 427,636 & 474,511 & $-46,875$ \\
\cline { 2 - 5 } & 2015 & 509,217 & 608,134 & $-98,917$ \\
\cline { 2 - 5 } & 2019 & 617,360 & 726,165 & $-108,805$ \\
\hline \multirow{5}{*}{ Países OPEP } & 2000 & 24,124 & 69,035 & $-44,911$ \\
\cline { 2 - 5 } & 2005 & 46,118 & 137,742 & $-91,624$ \\
\cline { 2 - 5 } & 2010 & 78,010 & 164,065 & $-86,055$ \\
\cline { 2 - 5 } & 2015 & 104,913 & 75,147 & 29,766 \\
\cline { 2 - 5 } & 2019 & 79,416 & 54,109 & 25,307 \\
\hline \multirow{5}{*}{ Sud América } & 2000 & 101,050 & 107,261 & $-6,211$ \\
\cline { 2 - 5 } & 2005 & 117,974 & 174,266 & $-56,292$ \\
\cline { 2 - 5 } & 2010 & 229,135 & 219,494 & 9,641 \\
\cline { 2 - 5 } & 2015 & 282,834 & 200,131 & 82,703 \\
\cline { 2 - 5 } & 2019 & 287,025 & 203,304 & 83,721 \\
\hline
\end{tabular}

Fuente: Bureau of Economic Analysis, USA, 2020.

La relación Trump-López Obrador, aunque inicialmente no fue sencilla, gradualmente fue definiendo las diversas agendas diversas respectivas y comunes, pues se habían negociado los temas de comercio (al aprobar el T-MEC en 2020), la seguridad fronteriza y la migración, la cuestión energética, entre otras. Con Biden en la presidencia de EU las cosas plantean relativa incertidumbre, pues esta nueva administración tiene otros enfoques y prioridades como la de las energías verdes, lo cual no encaja necesariamente con las políticas energéticas tradicionales de EU y de México respectivamente. 
REVISTA DE LA UNIVERSIDAD DEL ZULIA. 3é época. Año 13 N $^{\circ}$ 36, 2022 Oshiel Martínez Chapa et al. /// Comercio y desarrollo México-Estados Unidos: una aproximación, 28-55 DOI: http://dx.doi.org/10.46925//rdluz.36.03

En la era Trump, la política económica se centró en un conjunto de medidas consideradas como nacionalistas en el tenor de Make America Great Again, con lo cual obligó a renegociar el TLCAN, disminuyó los impuestos corporativos para repatriar empresas y empleos, entre otras acciones. No fueron pocos los gobiernos y corporaciones globalistas que cuestionaron tales medidas, considerándolas como anticuadas y contrarias al espíritu de libre comercio. Este repliegue proteccionista fue defendido por Trump en foros internacionales; ello en franca oposición a las políticas adoptadas por los gobiernos que le precedieron, los cuales contribuyeron en gran medida a la desindustrialización del país que fortaleció fundamentalmente a China, además de otros países.

En el contexto de la renegociación comercial (T MEC) México hasta el 2020 parecía tener más claras las oportunidades de crecer en la proveeduría y recepción de inversiones directas en manufactura, toda vez que se restringía a otros países a participar en el circuito de la producción. Sin embargo, está por ver si la administración Biden sigue la política de su predecesor de restringir China en EU y en otros países, o bien, decide una política de apertura e integración como la de los predecesores de Trump. También está por ver si la industria automotriz; la de mayor importancia en las manufacturas de México, va a seguir vigente. En suma, está por verse si se privilegiará una mayor convergencia e integración industrial y comercial con México, o en el peor de los casos, se siga un camino a una relación de pobre cooperación y conflicto.

La nueva administración de EU se ha reincorporado al Acuerdo de Cambio Climático de Paris y coloca así a las energías limpias como una prioridad de su gobierno. En ese sentido, las energías convencionales no tienen trato preferencial a juzgar por decisiones tales como cancelar el proyecto Keystone de Canadá y posponer los permisos para exploración de petróleo en Nuevo México, así como anunciar la intención de comprar vehículos eléctricos oficiales a la compañía Tesla. Con estas acciones algunos gobiernos estatales y sectores empresariales asociados al gas, petróleo, carbón, refinerías y sectores afines han manifestado su absoluto repudio.

Esto último no será una cuestión sencilla para Biden, pues se alistan acciones legales para contrarrestar sus medidas, ya que ponen en riesgo de perder empleos e ingresos a más de 10 millones de trabajadores y sus familias. La sustentabilidad económica de comunidades y regiones que han dependido de este tipo de industrias se halla en riesgo con dicha agenda energética. Cabe 
REVISTA DE LA UNIVERSIDAD DEL ZULIA. 3é época. Año 13 N $^{\circ}$ 36, 2022 Oshiel Martínez Chapa et al. /// Comercio y desarrollo México-Estados Unidos: una aproximación, 28-55

DOI: http://dx.doi.org/10.46925//rdluz.36.03

señalarse que esta política energética del gobierno de Biden tampoco será fácil de impulsar en México, dadas las prioridades del gobierno de López Obrador (2018-2024) en cuanto a mantener inversiones en las energías convencionales, pues ahí se advierten inversiones en la construcción y modernización de refinerías, oleoductos, exploración de pozos, generación de energía eléctrica y demás.

\subsection{Las remuneraciones y condiciones laborales}

Entre los desafíos presentes que México encara deben citarse a las bajas remuneraciones y las condiciones laborales adversas del grueso de los trabajadores. Para México las inversiones foráneas han sido beneficiosas en lo general, aunque los ingresos laborales no han experimentado progresos importantes durante mucho tiempo. De los diversos sectores económicos importantes que se encuentran en el país, destaca el automotriz por ser este considerado de alcance internacional. Este ha adquirido relevancia, pues el mismo genera una mayor contribución al producto nacional y emplea a un número creciente de trabajadores de las manufacturas.

Se trata del sector más pujante de México, del cual el 71 \% va dirigido a EU. En su momento la administración Trump consideró que México tomó indebidamente ventajas de este sector a expensas de la pérdida de empleos e ingresos de los trabajadores estadounidenses. La queja de los líderes sindicales de las armadoras estadounidenses era que no había forma de competir con los bajos salarios manufactureros de México, los cuales se ubican ahora mismo en \$3.91 en promedio la hora, contra los $\$ 39.03$ de ese país según se observa en la tabla 3.

Tabla 3 Costos de remuneraciones en la manufactura de México y EU (en USD)

\begin{tabular}{|l|c|c|c|}
\hline & 1997 & 2011 & 2019 \\
\hline EU & 23.00 & 37.81 & 39.03 \\
\hline México & 2.62 & 4.38 & 3.91 \\
\hline
\end{tabular}

Fuente: Elaborado por los autores en base a Conference Board (2020).

El bienestar del trabajador, considerando el salario promedio, presenta diferencias significativas; aun cuando México y EU buscan continuamente mejorar su relación de vecinos y socios. Las remuneraciones promedio de un trabajador, ya sea de Alemania, EU o Canadá son 
REVISTA DE LA UNIVERSIDAD DEL ZULIA. 3é época. Año 13 N $^{\circ}$ 36, 2022 Oshiel Martínez Chapa et al. /// Comercio y desarrollo México-Estados Unidos: una aproximación, 28-55 DOI: http://dx.doi.org/10.46925//rdluz.36.03

significativamente mayores a las de un mexicano. El PIB per cápita de México se halla muy lejos de alcanzar al de los países desarrollados.

De acuerdo con el sitio Tetakawi, México figura como un país adecuado para la manufactura por las siguientes razones:

Es la octava economía manufacturera más grande del mundo y ocupa el séptimo lugar en el mundo en el cálculo del índice competitivo de Deloitte. Las competencias de los empleados en la manufactura y una alta disposición a trabajar se están convirtiendo rápidamente en dos de las ventajas notables de México sobre otros países industrializados. Cuando se combinan costos más bajos, mayores habilidades y una actitud mejorada de los empleados, los fabricantes experimentan más productividad, mayor eficiencia y, en última instancia, clientes más satisfechos. Ésta es la ventaja competitiva de México (Tetakawi, 2021: 1).

De hecho, la situación económica prevaleciente en Europa, EU y demás países ha implicado un deterioro en las condiciones de trabajo, con lo cual se advierte estancamiento en las remuneraciones, mayor desempleo, así como una reducción en las prestaciones empresariales. De este modo, el panorama para los trabajadores y sus familias se complica ante la insuficiencia de los ingresos. La brecha existente revela que se trata de una crisis de tipo económico, social y, por supuesto, política. Para revertir esta situación se hace indispensable promover la calidad del empleo y el bienestar social, lo que implica fortalecer las instituciones a fin de inspirar la confianza entre los agentes económicos y sociales (Peralta, 2014).

La gráfica 2 muestra que el crecimiento del PIB per cápita de México apenas si experimentó un modesto cambio al pasar de 7896 USD en 1994 a 9567 en 2019. Por su parte el PIB per cápita de EU pasó de 37171 a 53056 USD en el periodo referido. Con ello se muestra que el crecimiento del ingreso del grueso de la población de México no obtuvo mejoría en el ingreso en el proceso de liberalización comercial; en este caso, la adhesión al GATT, al TLCAN y demás acuerdos comerciales.

Con la Gran Recesión de 2008, el desempleo creció en prácticamente todos los países. En el caso de EU, el impacto observado fue más inmediato, aunque luego se comenzó una recuperación modesta, mientras que en México dicha recuperación ha sido más lenta y, desafortunadamente la actual contingencia sanitaria de la Covid 19 ha estancado su crecimiento. 


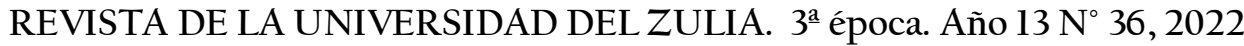
Oshiel Martínez Chapa et al. /// Comercio y desarrollo México-Estados Unidos: una aproximación, 28-55

Gráfica 2: Crecimiento del PIB per cápita de México y EU (1993-2019)

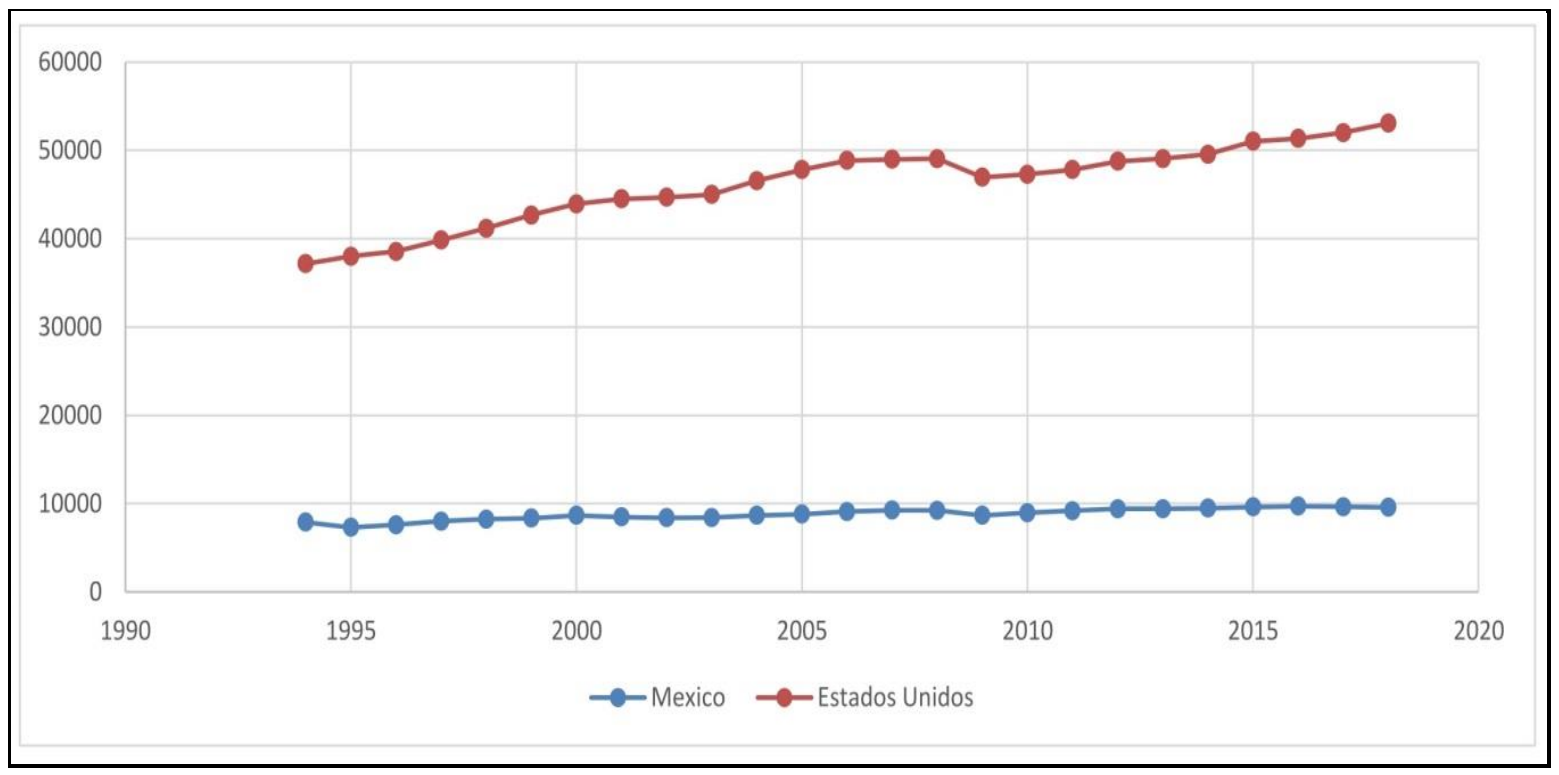

Fuente: World Bank (2020).

Por otro lado, en el sector agrícola, existe la autorización de trabajadores temporales mediante el programa $\mathrm{H}-2^{\mathrm{a}}$, lo cual ha permitido a mexicanos el trabajar en EU, una vez que el empleador ha cumplido el requisito de buscar previamente mano de obra local y no encontrarla. De este modo, el trámite y la aprobación suele ser más expedita. Aunque esto puede verse como una gran oportunidad para los trabajadores mexicanos, se ha encontrado la existencia de ciudadanos estadounidenses desempleados que desearían trabajar en el campo. Sin embargo, los bajos salarios y las largas jornadas los mantienen lejos de estos oficios. Se advierte, pues, una práctica de discriminación laboral hacia los trabajadores temporales, tanto en salarios como en jornadas extenuantes (Palacios, 2010).

Debe, adicionalmente, considerarse el aumento de personas con ambas nacionalidades y con derechos para trabajar, para lo cual se requiere de las instancias fiscales el homologar la recaudación de impuestos para no incurrir en la doble fiscalización para el mismo trabajo, o que el trabajador pague impuestos en el sistema del cual no obtiene los beneficios de protección social (Martin y Mejía, 2009).

\subsection{Los Derechos Humanos}


REVISTA DE LA UNIVERSIDAD DEL ZULIA. 3é época. Año 13 N$^{\circ}$ 36, 2022 Oshiel Martínez Chapa et al. /// Comercio y desarrollo México-Estados Unidos: una aproximación, 28-55 DOI: http://dx.doi.org/10.46925//rdluz.36.03

En este apartado debe señalarse que el gobierno mexicano ha establecido reiteradamente su compromiso de defender los derechos humanos como política de Estado. El mismo ha reconocido que no se han advertido avances significativos hacia su cumplimiento; por el contrario, se ha visto disminuido ante el aumento de las violaciones de estos, los cuales se llegan a conocer públicamente. Las denuncias de violaciones a los Derechos Humanos de mexicanos en suelo estadounidense siguen al alza. Sin embargo, les ocurre lo mismo a los ciudadanos de otros países en el suelo mexicano. Ello debe obligar a la autoridad competente a actuar en consecuencia y no dar lugar a situaciones de impunidad.

Desafortunadamente, esta condición social es asimilada por las nuevas generaciones de jóvenes como una cultura "normal" de violencia, corrupción e impunidad. El estatus de México, por tanto, se califica como "parcialmente libre" (65 en escala de 100). En el año 2016 la Libertad de Prensa se calificó como "no libre”, y la Red como "parcialmente libre”. Esta calificación se confirma al conocerse, en el presente 2017, de las prácticas del gobierno contra las comunicaciones privadas. En contraste EU, por su parte, se califica como "libre" en los tres apartados, con un puntaje de 89 (Freedom House, 2017).

En el caso de los menores de edad e hijos de indocumentados mexicanos, los Derechos Humanos deberán respetarse, considerando el bien superior de la familia. En ese sentido, ambos gobiernos requieren aplicar una política migratoria que ofrezca mecanismos legales de reunificación familiar más expeditos, informando oportunamente a los deportados. Muchos padres deportados no inician un proceso de reunificación por ignorancia o temor, provocando una separación familiar definitiva (Kline, 2013). La situación en México ha movido a organizaciones defensoras de los derechos humanos a buscar un diálogo con la presidencia de México para apoyar en concretar soluciones (Amnistia Interncional, 2020).

\subsection{Seguridad fronteriza y cooperación contra el crimen}

De acuerdo con el entonces presidente de Estados Unidos, Donald Trump (2016-2020), la seguridad fronteriza se constituyó en una prioridad de su gobierno. De hecho, fue uno de los temas de su campaña electoral y la convirtió en una promesa que buscó hacer realidad en su gestión, dados los reclamos de su base electoral. Para el gobierno en cuestión la seguridad 
REVISTA DE LA UNIVERSIDAD DEL ZULIA. 3é época. Año 13 N $^{\circ}$ 36, 2022 Oshiel Martínez Chapa et al. /// Comercio y desarrollo México-Estados Unidos: una aproximación, 28-55 DOI: http://dx.doi.org/10.46925//rdluz.36.03

fronteriza requirió la conjunción de recursos a partir de la tecnología, la infraestructura fronteriza del personal y todo el apoyo gubernamental. La continuación de la construcción del muro en la frontera con México y demás acciones de vigilancia y reforzamiento territorial fueron parte de la estrategia implementada para detener los flujos de drogas, de indocumentados, de terroristas y demás amenazas para la seguridad nacional. Los entonces adversarios políticos de la administración de Trump consideraron la percepción de amenaza a la seguridad del país como una sobredimensión del problema y, que no requería de la aplicación de recursos extraordinarios. La renegociación del TLCAN, a petición expresa de Trump, debió verse en el contexto de hacer grande América otra vez, lema fundamental de su campaña política a la presidencia.

En materia de seguridad fronteriza la nueva administración de Joe Biden (2021) ha tomado acciones y ha ordenado detener las deportaciones masivas, frenar la construcción del muro, además de prometer considerar un eventual alivio migratorio. Sin embargo, estados de la Unión Americana como Texas, Arizona, Florida, además de otros, han tomado acciones legales para impedir que se materialicen estas órdenes ejecutivas, pues ninguna de estas puede colocarse por encima de lo establecido por la Constitución. Por otro lado, en el sur de México ocurre una presión extraordinaria de parte de las caravanas de migrantes dado su empeño en llegar a EU. Esta posición coloca al gobierno mexicano en una situación incómod a dadas las acusaciones de violaciones de los derechos humanos y de incurrir en contradicciones con la realidad, pues se cuestiona que el gobierno mexicano haya firmado el Pacto Mundial de Migración y en ese sentido deba velar por el interés de los migrantes.

Tanto México como EU, son origen, tránsito y destino de hombres, mujeres y niños víctimas de tráfico de personas. En el ataque al delito de tráfico de personas, se espera de México una mejora significativa, pues el país ha permanecido en el mismo nivel de clasificación desde 2010. Se ha reconocido la complicidad de autoridades en el ilícito, principalmente a nivel local, lo cual es un problema serio no resuelto. El tráfico de personas es favorecido por el crimen organizado y el turismo sexual en ambos países. Aunque el gobierno de los EU cumple completamente los estándares mínimos para la eliminación del tráfico de personas, se ha recomendado acentuar su trabajo en el área de la explotación laboral y sexual. El Departamento de Estado de EU considera que existe una fuerte cooperación con las fuerzas del orden de 
REVISTA DE LA UNIVERSIDAD DEL ZULIA. 3é época. Año 13 N $^{\circ}$ 36, 2022 Oshiel Martínez Chapa et al. /// Comercio y desarrollo México-Estados Unidos: una aproximación, 28-55 DOI: http://dx.doi.org/10.46925//rdluz.36.03

México, lo cual ha permitido arrestos de traficantes de personas operando en ambos países (US Departament of State, 2020).

Según el Banco Mundial (Enamorado et al., 2013) se ha encontrado evidencia de una relación negativa entre el crecimiento económico y el nivel de crimen organizado asociado al tráfico de drogas; en tanto que este mismo efecto no se detecta para el denominado crimen común. La migración de mexicanos hacia territorio estadounidense se ha encontrado correlacionada positivamente al aumento en criminalidad en los municipios fronterizos, pero negativamente en otras comunidades. A partir de 2005, los migrantes mexicanos hacia el EU, son en general menos pobres y mayormente educados (Escobar Latapí et al., 2013).

En México organismos como la Comisión Nacional de Derechos Humanos y Human Right Watch, entre otros, han denunciado al gobierno de la 4T por sus acciones de política migratoria, aun cuando este se ha comprometido a invertir en el sur de México y a dar un trato de justicia al migrante. Es pertinente destacar que el gobierno de EU desde hace varias décadas ha presionado al de México para poner orden en la casa y enfrentar a las bandas criminales, pero también a restringir, en lo posible, el ingreso de indocumentados por el sur. Al no poder llegar a EU miles de personas se han quedado a vivir en México. Esto último muestra que son enormes los riesgos que conllevan los flujos migratorios, todo lo cual requiere de acciones conjuntas de los países involucrados para impulsar políticas de desarrollo regional.

\subsection{Migración}

La crisis de la migración en las fronteras norte y sur de México, agravada por las caravanas de indocumentados de Centro América y de otros países es un claro ejemplo de lo que se señala en líneas anteriores. En el contexto del Pacto Global de Migración del 2018 y la política migratoria de Biden, se ha dado un aliento al fenómeno, creándose así una crisis humanitaria sin precedente. Cientos de miles de inmigrantes, y las mismas autoridades encargadas de resguardar la frontera encaran una situación complicada (Harshbarge, 2021).

En la administración de Trump, EU se inició un cambio en la política de migración cuyo propósito fundamental se circunscribe en el reforzamiento de las fronteras y en la intención de liberarse así de las imposiciones de los organismos internacionales. En la agenda del Pacto 
REVISTA DE LA UNIVERSIDAD DEL ZULIA. 3é época. Año 13 N $^{\circ}$ 36, 2022 Oshiel Martínez Chapa et al. /// Comercio y desarrollo México-Estados Unidos: una aproximación, 28-55 DOI: http://dx.doi.org/10.46925//rdluz.36.03

Mundial de Migración se pretende impulsar las fronteras abiertas con el argumento de la solidaridad e inclusión racial.

Sin embargo, se ha documentado la existencia de grupos de interés que impulsan y financian con la intención de introducirse de forma indocumentada en EU, creando una alteración de las buenas relaciones entre estos países, los cuales habían permitido hasta ahora una convivencia respetuosa y productiva. En el área legislativa debe tenerse presente que quienes impulsan el cambio de sistema político actual en México presentaron una nueva política migratoria como propia, cuando en realidad solo era el plan de la Organización de las Naciones Unidas (ONU) en el tema migratorio aprobado en Marrakech. Debe tenerse presente que EU no firmó este Acuerdo Migratorio, buscando con ello conservar su soberanía en cuanto a quién y cómo se autoriza la entrada a su país.

EU desde antes de la "crisis humanitaria" propuso fortalecer la protección de la frontera con la guardia nacional y, como es normal en toda vivienda en México que se precie de proteger a una familia y sus bienes, construir un muro para mejorar la protección del país. El hecho de que México realizó lo que EU ya antes había propuesto, y sostenido por su presidente Trump de impedir el paso ilegal por la frontera, y que esa misma acción ahora México la repite con el gobierno actual de EU, manifiesta que la política de EU con Trump en ese entonces fue correcta en lo referente a protección fronteriza.

Ahora la política de Biden de abrir las fronteras de EU ha generado un caos migratorio; y aunque la reunión diplomática entre EU y México para tratar el problema concluyó haciendo una declaratoria pública del lema de la ONU de "garantizar una migración segura y ordenada", la acción del gobierno de México enviando 12,000 elementos de su Guardia Nacional a su frontera sur, refleja que en realidad el gobierno de EU urgentemente requirió del apoyo de México para frenar la avalancha que su oferta de apertura fronteriza ha generado.

En el contexto del análisis actual debe tenerse presente que México ha iniciado un cambio gubernamental hacia una economía social, la cual ha mostrado con creces sus limitaciones para hacerla realidad de éxito, pues a través de la historia se ha constatado su limitado avance en los temas de libertades esenciales como el emprendimiento, la innovación, la libre expresión y de respeto por los derechos humanos. 
REVISTA DE LA UNIVERSIDAD DEL ZULIA. 3é época. Año 13 N$^{\circ}$ 36, 2022 Oshiel Martínez Chapa et al. /// Comercio y desarrollo México-Estados Unidos: una aproximación, 28-55 DOI: http://dx.doi.org/10.46925//rdluz.36.03

Los procesos migratorios han existido siempre y son diversas las razones por las cuales se siguen reproduciendo. En el siglo pasado y en el presente la migración se ha asociado al fracaso de políticas económicas adoptadas por gobiernos en los diferentes continentes. En América Latina desde la década de las ochenta dichas políticas se significaron por una reducción en los niveles de bienestar derivado de un proceso de desmantelamiento del Estado de bienestar y de fuerte concentración de la riqueza. En general, estas políticas fueron adversas para el grueso de la población, de modo tal que millones de personas experimentaron la migración del medio rural al urbano en sus respectivos países, pero también hacia los EU, Canadá, Europa, Japón, por mencionar los principales destinos.

El crecimiento de la migración debe explicarse, adicionalmente, al fracaso de no contener la violencia, el narcotráfico, las pandillas y el empobrecimiento de vastas regiones del Continente. Igualmente se advierte las dificultades para que en estos países se pueda experimentar la movilidad socioeconómica a través de la educación formal y empleos bien remunerados.

El asunto migratorio está vigente y aun se refuerza, pues desde 2016 se han observado oleadas de caravanas de ciudadanos procedentes de Haití, Cuba, Centroamérica, pero también de la India, Bangladesh y demás países de África. Estas caravanas tenían como destino a los EU, pero su paso obligado es a través de México. Ello ha significado la permanencia de migrantes en las zonas fronterizas del sur, del interior y del norte de México. De hecho, una nueva crisis migratoria de 2018, 2019 y 2021 ha sido motivo para presionar al gobierno mexicano a fin de que coopere con mayor determinación en la contención de dichas caravanas.

De acuerdo con la gráfica 3 la población indocumentada en EU ha crecido y tiene mayor presencia a lo largo del periodo. En lo que concierne a deportaciones y retornos, de nueva cuenta se observa un crecimiento importante. Llaman la atención algunos años, como el de 2008 con el gobierno de Bush, ya en el contexto de la Gran Recesión. También es notorio el periodo en el que gobernó Obama, considerado el campeón de las deportaciones. Su retórica en favor de reforma migratoria contrastó con una situación de deportaciones sin precedentes. Esta situación pone de manifiesto dos cosas: La primera, el deterioro constante de la economía de México, Centro América y el Caribe, además de otras naciones y, segundo, el atractivo de EU como nación que 
REVISTA DE LA UNIVERSIDAD DEL ZULIA. 3é época. Año $13 \mathrm{~N}^{\circ}$ 36, 2022 Oshiel Martínez Chapa et al. /// Comercio y desarrollo México-Estados Unidos: una aproximación, 28-55 DOI: http://dx.doi.org/10.46925//rdluz.36.03 puede aliviar la situación de millones de personas agobiadas por adversidades económicas y políticas.

Gráfica 3: Población deportada y retornada de Estados Unidos (1986-2019)

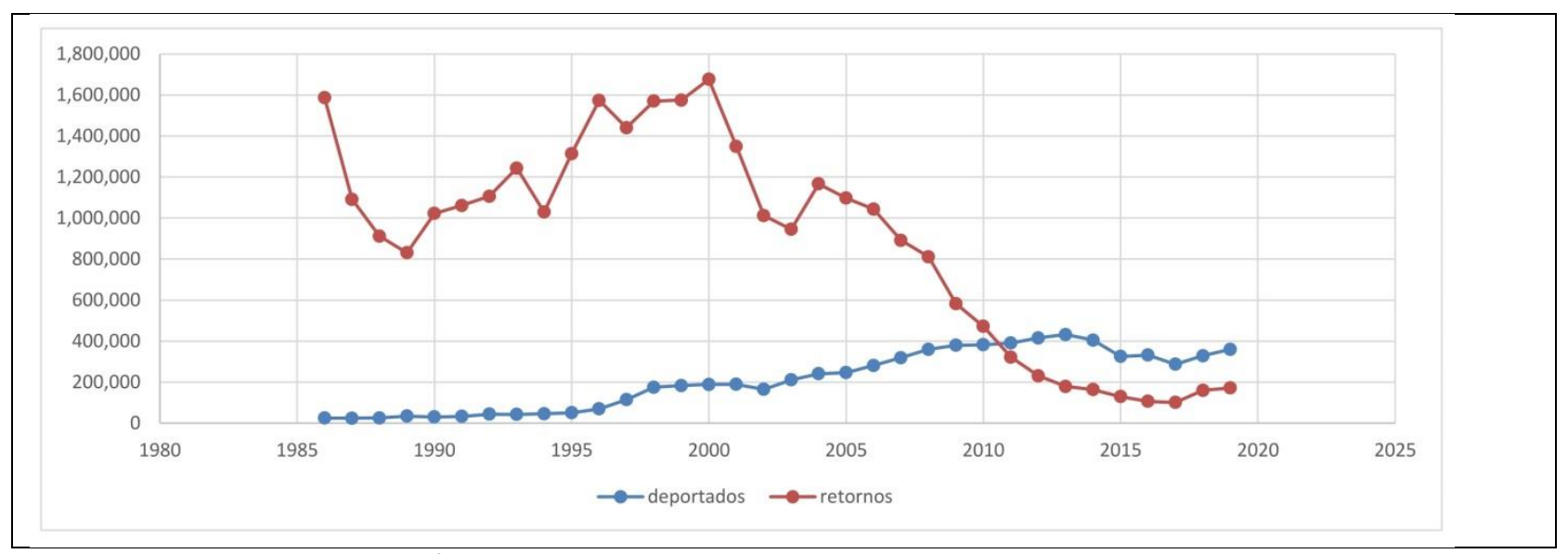

Fuente: US Department of Homeland Security (2020).

Nota: ${ }^{1}$ Las deportaciones son el movimiento obligatorio y confirmado de un extranjero inadmisible o deportable fuera de los Estados Unidos basado en una orden de deportación. ${ }^{2}$ Los retornos son el movimiento confirmado de un extranjero inadmisible o deportable fuera de los Estados Unidos que no se basa en una orden de expulsión.

Con la llegada de D. Trump a la presidencia de EU las órdenes ejecutivas en materia de migración consideraron sujetos a deportación inmediata individuos en los siguientes casos: Convictos de un crimen; acusados de una falta penal, aun cuando el caso no ha sido resuelto; comisión de una acción que constituye una ofensa criminal; comisión de fraude o presentación falsa ante una agencia de gobierno; abuso de algún programa de beneficios públicos; tráfico de drogas o trata humana, prostitución, lavado de dinero; con una orden de deportación o es un riesgo para la seguridad pública o nacional, comisión de delitos considerados graves como terrorismo, espionaje, sedición, abuso doméstico o a un menor de edad, así lo considere el agente de inmigración.

Para estos ciudadanos el retorno a sus países plantea escenarios de oportunidades en el mejor de los casos. Si el deportado ahorró dinero o se preparó para esta situación puede emplearse de manera formal. La informalidad es una salida; de hecho, la más común. No obstante, en términos realistas prevalecen en la mayoría de los casos pobreza, crimen y dificultades para 
REVISTA DE LA UNIVERSIDAD DEL ZULIA. 3é época. Año 13 N $^{\circ}$ 36, 2022 Oshiel Martínez Chapa et al. /// Comercio y desarrollo México-Estados Unidos: una aproximación, 28-55 DOI: http://dx.doi.org/10.46925//rdluz.36.03

la reinserción en el país de origen. La cuestión es que regresar a EU parece lo más atractivo, dadas las acciones favorables hacía los migrantes de la administración Biden y de organizaciones no gubernamentales: estímulos económicos, viaje gratuito al interior de EU desde la frontera, hospedaje en hoteles, liberación de las autoridades migratorias aún sin una cita futura para comparecer ante la corte y una alta posibilidad de obtener en el futuro la ciudadanía.

El trayecto hacia los EU significa riesgos y costos elevadísimos dada la existencia de 'coyotes', crimen organizado, vigilancia de autoridades migratorias y demás obstáculos para los migrantes. La situación de que haya migrantes que no logran cruzar a EU plantea un incremento importante de solicitudes de asilo y refugio en México. Sin embargo, en el país no se tiene la capacidad para dar respuesta oportuna a estos demandantes.

Por otro lado, debe señalarse el que las deportaciones se anuncian con tiempo y las redadas se planifican y ocurren en lugares que el gobierno considera de interés estratégico. Con estas acciones se pretende disuadir a los nuevos entrantes de la no conveniencia de aventurarse en territorio estadounidense. Quienes viven de manera indocumentada en EU están muy conscientes de su elevado riesgo y que la deportación es algo que, eventualmente puede ocurrir.

Ante lo anteriormente expuesto, los consulados y embajadas recomiendan a estas familias tener documentos a la mano a fin de protegerse, en lo posible. Se debe prever que se haría en casos de detenciones y deportaciones. El gobierno mexicano no debe dejar a esta población a la deriva, pues en muchos casos tienen hasta 30 años de vivir en los EU. Estas familias pueden poseer propiedades, empleos estables, deudas, activos, formación educativa, expectativas y, por tanto, viven en constante zozobra e incertidumbre.

Sería muy deseable que el gobierno de México tenga una política que le otorgue el acompañamiento necesario a los retornados a fin de disminuir, en lo posible, la incertidumbre que significa esta realidad. Esta población deportada se halla expuesta a ser atrapada incluso por el crimen organizado. Estas personas retornadas han contribuido con sus remesas al desarrollo de sus comunidades o ciudades. Requieren ser atendidos debidamente y tener una valoración social y gubernamental de aquellas naciones de origen.

De acuerdo con el documento "Políticas Multinivel para el retorno y la (re) inserción de migrantes mexicanos y sus familias" de Cruz y Hernández (2018), se asienta la ausencia de 
REVISTA DE LA UNIVERSIDAD DEL ZULIA. 3é época. Año 13 N $^{\circ}$ 36, 2022 Oshiel Martínez Chapa et al. /// Comercio y desarrollo México-Estados Unidos: una aproximación, 28-55 DOI: http://dx.doi.org/10.46925//rdluz.36.03

coordinación gubernamental a fin de atender los perfiles de estos ciudadanos retornados. Deseable es apoyarles en los trámites de identificación y demás necesidades como la atención médica, cuando se requiere esta. Entre los aspectos que debe implementar el gobierno en su política de atención a migrantes en retorno es la de la política de inclusión a la sociedad, además de los apoyos legales y económicos indispensables para llevar su vida con mayor certidumbre.

Por otro lado, las bajas remuneraciones y las deficientes condiciones laborales en México empobrecen a los trabajadores, y a la vez, limitan el crecimiento de la clase media. Dicha condición propicia la agudización de los problemas que encaran los ciudadanos desesperados que buscan en otro(s) país(es) lo que su tierra les niega. La historia muestra que la inmigración es un fenómeno explicado por la necesidad de mejorar las condiciones de vida, al mismo tiempo de escapar de las guerras y de violencia agobiante. En el desarrollo de las naciones resulta fundamental el respeto a las libertades civiles y el apego al Estado de derecho; no hacerlo entraña sufrimiento y es, por tanto, una tragedia social costosa.

México y EU deben revisar los acuerdos migratorios a fin de agilizar la participación laboral a los ciudadanos fronterizos y reducir así la incertidumbre en la que viven millones de personas. Un arreglo migratorio ordenado reduciría la incertidumbre de los migrantes y sus familias. Traería beneficios para las partes, al proveerse fuerza de trabajo a los EU y mejorar las condiciones de ingresos económicos de las regiones pobres de México y de otros países. Ello, aunque es deseable, se ha visto que no es un asunto simple. Sin embargo, debe seguirse en la agenda en cuestión, sin que ello implique que el gobierno mexicano renuncie a su obligación de invertir en desarrollo social. A fin de reducir estos rezagos, la política económica de México deberá ser más inclusiva en lo social, pero estratégica en lo comercial.

Otros problemas que México enfrenta lo constituyen el deficiente sistema de salud y educación pública, el limitado capital financiero para trabajar, el déficit en la infraestructura para el desarrollo regional, entre otros. De hecho, los indicadores de bienestar revelan que los bajos ingresos se asocian con la pobreza y la falta de oportunidades para mejorar las condiciones de vida material del grueso de la población. Dentro de las acciones a seguirse se halla el fortalecer las instituciones del mercado laboral y promover la formalidad y el empleo digno, con lo cual se 
REVISTA DE LA UNIVERSIDAD DEL ZULIA. 3é época. Año 13 N $^{\circ}$ 36, 2022 Oshiel Martínez Chapa et al. /// Comercio y desarrollo México-Estados Unidos: una aproximación, 28-55 DOI: http://dx.doi.org/10.46925//rdluz.36.03

traería consigo mayor cantidad de aportantes y así sustentar a largo plazo el modelo de seguridad y de acceso al bienestar en la edad de jubilación (Martínez et al., 2015).

\section{Conclusiones}

En este trabajo se ha planteado el objetivo de analizar la agenda de comercio y desarrollo binacional entre México y Estados Unidos (EU), en lo que concierne a los apartados comercio bilateral, remuneraciones y relaciones laborales, derechos humanos, seguridad fronteriza y cooperación contra el crimen, así como migración. Para México es un imperativo mejorar sus acuerdos comerciales existentes y a la vez diversificar su comercio exterior, especialmente en la coyuntura de proteccionismo latente. Se han señalado aspectos relativos a las remuneraciones y condiciones laborales. Se ha destacado la seguridad fronteriza y la cooperación contra el crimen por ser estos aspectos indispensables. La agenda de la migración cobra relevancia ahora mismo y debe abordarse buscando colocar el interés de México en la misma.

Los tratados comerciales requieren de una continua revisión a fin de encontrar vías de mejoramiento, pues no solo debe privilegiarse los aspectos comerciales. En ese sentido, no es ocioso insistir en una agenda de desarrollo social y de cooperación respetuosa, para lo cual es preciso reducir los conflictos de índole comercial de aquellos que se hallan presentes en toda la vasta geografía del mundo.

Debe señalarse que la inversión extranjera de EU en México ha venido creciendo significativamente, de modo que ya son muchas las empresas adquiridas por parte de grandes corporaciones nacionales y extranjeras. Destacan bancos, cadenas comerciales, manufactureras, empresas de servicios especializados, entre otros. Existen, además de inversiones crecientes en sectores diversos como el turismo, aviación, minería, energía, gas, petróleo, por mencionar algunas.

De igual modo, se espera que las políticas estadounidenses tengan como fin mejorar la relación con México más allá de los aspectos estrictamente comerciales, tomando en cuenta las acciones de otros países como China y los miembros de la Unión Europea. Está claro que ningún país tiene todo por ganar en el CI; por tanto, se plantea la necesidad de adecuarse a la dinámica compleja que entrañan las relaciones binacionales. 
REVISTA DE LA UNIVERSIDAD DEL ZULIA. 3é época. Año 13 Nº 36, 2022 Oshiel Martínez Chapa et al. /// Comercio y desarrollo México-Estados Unidos: una aproximación, 28-55 DOI: http://dx.doi.org/10.46925//rdluz.36.03

Entre los asuntos de la agenda bilateral deben señalarse que merecen priorizarse, entre otros, los siguientes: 1). La petición de sectores mexicanos para que el gobierno de EU reduzca los subsidios a su sector agrícola; 2) los retrasos y complicaciones que sufren los transportistas mexicanos en las aduanas estadounidenses; 3) la cooperación para frenar la causa de la migración de México y de otros países; 4) la violación a Derechos Humanos y la incertidumbre respecto al futuro de mexicanos en territorio estadounidense; 5) el contrabando de armas y demás bienes en forma ilegal hacia México; 6) el tráfico de personas y de drogas hacia EU; 7) la resolución expedita de controversias comerciales.

\section{Referencias}

Bejarano Copo, H., Molero Oliva, L., Villegas Pocaterra, E., Borgucci García, E. (2020). Ecuador y la Alianza del Pacifico: Estudio comparativo sobre oportunidades de crecimiento vía sector externo. Revista Venezolana De Gerencia,25(4), 628-647. Recuperado a partir de: https://www.produccioncientificaluz.org/index.php/rvg/article/view/35228

Benacek, V. (2010). International Trade Theory and Its Methodology: Explaining the Structure of Migration Flows. Facets of Migration in Contemporary Europe - Interdisciplinary Approaches to Specific Challenges.

Biden, J. (2021). Memorandum for the Secretary of State on the Emergency Presidential Determination on Refugee Admissions for Fiscal Year 2021. White House. Recuperado a partir de:https://www.whitehouse.gov/briefing-room/presidential-actions/2021/04/16/memorandum-forthe-secretary-of-state-on-the-emergency-presidential-determination-on-refugee-admissions-forfiscal-year-202l/

Bureau of Economic Analysis, USA. (2020). Recuperado a partir de: https://www.bea.gov/data/economic-accounts/international

Burfisher, M., Robinson, S., Thierfelder, K. (2001). The impact of Nafta on the United States. In Journal of Economic Perspectives, vol. 5, num 1. Recuperado a partir de:https://pubs.aeaweb.org/doi/pdfplus/10.1257/jep.15.1.125

Conference Board (2020). International Comparisons of Hourly Compensation Costs in Manufacturing. Recuperado a partir de: https://www.conferenceboard.org/ilcprogram/index.cfm?id=38269

Cruz Piñeiro, R., Hernández Hernández, A. (2018). Políticas Multinivel para el retorno y la (re) inserción de migrantes mexicanos y sus familias. Documento de trabajo. Colegio de la Frontera Norte y Comisión Nacional de los Derechos Humanos, México. Recuperado a partir de: https://www.colef.mx/estudiosdeelcolef/informe-politicas-multinivel-el-colef- 
REVISTA DE LA UNIVERSIDAD DEL ZULIA. 3é época. Año 13 Nº 36, 2022 Oshiel Martínez Chapa et al. /// Comercio y desarrollo México-Estados Unidos: una aproximación, 28-55 DOI: http://dx.doi.org/10.46925//rdluz.36.03 cndh/?fbclid=IwAR2M9s3TClNB9pWr5oRJhi2aTrlFuNw9Rv9HDG4hv9oL3GXnXn3pCQwTUP A

Daniels, J. (2009). Negocios internacionales, Prentice Hall.

Enamorado, T., López-Calva, J., Rodríguez-Castelán, C. (2013). Crime and Growth Convergence. Evidence from Mexico. World Bank, pp.1-12. Recuperado a partir de: https://openknowledge.worldbank.org/handle/10986/16946

Escobar Latapí, A., Lowell, L., S. Martin (2013). Diálogo Binacional sobre migrantes mexicanos en Estados Unidos y México. $1^{\underline{a}}$ ed. Ciudad de México: Centro de Investigaciones y Estudios Superiores en Antropología, pp.48-9-51. Recuperado a partir de: https://www.cisan.unam.mx/migracionRetorno/ABRIL\%2026\%20INFORME\%20FINAL\%20dial ogo $\% 20$ binacional $\% 20$ ESP2.pdf

Freedom House (2017). Freedom in the world 2017. Freedom House, pp.22-24. Recuperado a partir de: http://www.freedomhouse.org/report/freedom-world/freedom-world-2017

Harshbarge, D. (2021, 21 de abril). I visited the southern border. Biden's border crisis is worse than reported. Citizen Tribune. Recuperado a partir de: https://www.citizentribune.com/news/editorial/ivisited-the-southern-border-biden-s-border-crisis-is-worse-than-reported/article_99cf2ela-a2aflleb-9be6-67156342c5b5.html

Internacional, A. (2020). Carta abierta: Solicitud de reunión de alto nivel entre el presidente de México y Amnistía Internacional. Recuperado a partir de: https://www.amnesty.org/es/documents/amr4l/1832/2020/es/

Kline, V. (2013). Separación familiar por las políticas y prácticas migratorias en los EUA y su impacto en México. Instituto para las Mujeres en la Migración, AC, pp.9-10. Recuperado a partir de: http://www.cisan.unam.mx/migracionRetorno/Separacion\%20Familiar\%20y\%20su\%20impacto\% 20en\%20Mexico.pdf

Martin, P. y Mejia, A. (2009). Comparative Overview of U.S. and Mexican Federal Employment Taxes. International Tax Journal, (noviembre-diciembre 2009), pp.61-68.

Martínez Chapa, O., Salazar Castillo, J y Efraín Jaime Ang (2015). La Relevancia del empleo: concepciones y desafíos presentes, revista Realidades, año 5, número 1, UANL, mayo-octubre. Recuperado a partir de: http://realidades.uanl.mx/index.php/realidades/article/view/ela5nl

Martínez Chapa, O., Salazar Castillo, J. E., y Quispe Aruquipa, S. R. (2021). Régimen político mexicano y su legado de reformas económicas. Revista Venezolana De Gerencia, 26. (Número Especial 5), 315-330. https://doi.org/10.52080/rvgluz.26.e5.21

Mendoza Cota, J. (2021). Determinantes del comercio entre Estados Unidos y México bajo el TMEC. Norteamérica, Revista Académica del CISAN-UNAM. https://doi.org/10.22201/cisan.24487228e.2021.2.478 
REVISTA DE LA UNIVERSIDAD DEL ZULIA. 3é época. Año 13 N$^{\circ}$ 36, 2022 Oshiel Martínez Chapa et al. /// Comercio y desarrollo México-Estados Unidos: una aproximación, 28-55 DOI: http://dx.doi.org/10.46925//rdluz.36.03

Ortiz Valenzuela, E. (2020). Normativa de origen automotriz del acuerdo de alcance parcial comercial N 28 Colombia-Venezuela. Revista De La Universidad Del Zulia, 5(11), 40-55. Recuperado a partir de: https://produccioncientificaluz.org/index.php/rluz/article/view/31026

Palacios, I. (2010). Los jornaleros tamaulipecos y el programa H-2A de trabajadores huéspedes. Editorial Plaza y Valdés, pp.49-65.

Peralta, E. (2014). “El empleo: más causa que efecto de crisis”, Comercio Exterior, volumen 64, núm. 1, enero-febrero.

Ray, D. (2002). Economía del desarrollo, Antoni Bosch Editor, S.A.

Reyes, A. (2021). México-EU: una agenda bilateral agridulce, El Economista, México. Recuperado a partir de: https://www.eleconomista.com.mx/revistaimef/Mexico-EU-una-agenda-bilateralagridulce-20210209-0035.html

Rybczynski, T. M. (1955). Factor endowment and relative commodity prices. Economica, 22(88), 336341 .

Samuelson, P. y Nordahus W. (2010). Economía con aplicaciones a Latinoamérica. 19a ed. Editorial McGraw Hill.

Stiglitz, J. (2011). El malestar en la globalización, Punto de lectura.

Terrazas y Basante M. y G. Garza L. (2012). Las relaciones México-Estados Unidos, 1756-2010, México, UNAM, Vol. 1, cap. 3 [La independencia mexicana y la definición de las fronteras], pp. 87112.

Tetakawi (2021). Manufacturing in México. Documento de trabajo. Recuperado a partir de: https:/tetakawi.com/manufacturing-in-mexico/why-manufacture-in-mexico/

US Department of Agriculture (2020). Mexico 2020 Export Highlights. Recuperado a partir de: https://www.fas.usda.gov/mexico-2020-export-highlights

US Department of Homeland Security (2020). Yearbook Immigration State. Recuperado a partir de: https://www.dhs.gov/immigration-statistics/yearbook/2019/table39

US Departament of State (2020). Trafficking in persons report. June 2020. US Departament of State Publication, pp.353-357. Recuperado a partir de: https://www.state.gov/reports/2020-trafficking-inpersons-report/

US Departament of State (2021). Mexico. Bureau of Western Hemisphere Affairs. Recuperado a partir de: https://www.state.gov/countries-areas/mexico/

World Bank (2020). GDP per capita. Recuperado a partir de: https://data.worldbank.org/indicator/NY.GDP.PCAP.CD 